\title{
CAREER PROGRESS AND CAREER BARRIERS: WOMEN MBA GRADUATES IN CANADA AND THE UK
}

\author{
Dr Ruth Simpson \\ School of Business and Management \\ Brunel University \\ Uxbridge \\ Middlesex, UB8 3PH \\ Email: r.simpson@brunel.ac.uk \\ Dr Jane Sturges \\ Kings College, London \\ Email: jane.sturges@kcl.ac.uk \\ Professor Adrian Woods \\ School of Business and Management \\ Brunel University \\ Uxbridge \\ Middlesex UB8 3PH \\ Email: Adrian.woods@brunel.ac.uk
}

Professor Yochanan Altman

London Metropolitan University

Email: Y.Altman@unl.ac.uk

Ruth Simpson is senior lecturer at the School of Business and Management, Brunel University and a member of the university's Center for Research in Emotion Work. Her research interests include careers, gender and management development and gender in organizations 


\title{
CAREER PROGRESS AND CAREER BARRIERS: WOMEN MBA GRADUATES IN CANADA AND THE UK
}

\begin{abstract}
This article explores the career progress of female MBA graduates in Canada and the UK and the nature of career barriers experienced in each context. Results suggest that while Canadian women have similar career profiles to men, women in the UK lag behind their male counterparts after graduation from the course. At the same time, UK women encounter more intractable career barriers in the form of negative attitudes and prejudice. A model of the 'MBA effect' is proposed in terms of how the qualification may impact on career barriers. This incorporates three different types of barriers which are seen to operate at the individual level (person centred barriers) and at the intermediate/organizational level (organizational culture and attitudes, corporate practices) as well as, at the macro level, the impact of legislative frameworks. Results from the UK and Canadian surveys are discussed in relation to this model and in the context of feminist theory and women in management literature.
\end{abstract}

Key words: gender, careers, career barriers, MBA 


\section{Introduction}

Over the last 30 years the number of women pursuing managerial and professional careers has greatly increased. Between 1971 and 1996 the proportion of women in management in Canada doubled from 16\% to 33\% (Statistics Canada, 1997) with similar rises in the UK (Institute of Management, 1998). However, in both countries women are still in the minority at all management levels and the further up the hierarchy the greater the disparity. For example, only $6 \%$ of board members in Canada and 3.6\% in the UK are women (Catalyst, 2000a; Institute of Management, 1998). As Burke (1994) in Canada and Bickersaffe (1992) in the UK suggest, many women prepare themselves for careers by undertaking an MBA - often seen as a means for breaking through the glass ceiling into senior management positions. Accordingly, women now account for approximately one third of MBA students in both Canada and the UK, an increase from 16\% in 1970 (Business Week, 1997; AMBA, 1996). In fact, the MBA is often perceived as a passport to senior management (Baruch et al, 2004) and as Finney (1996) suggests, increasingly a pre-requisite for both men and women who aspire to senior positions. The proliferation of courses and rise in student numbers (see Stern, 2002) is testimony to the perceived benefits from the qualification. However, despite its popularity, little is known about the impact of the MBA on women's careers or whether the MBA can help overcome career barriers. Drawing on Canadian and UK data, this paper addresses the above research gap by exploring the career progress of women MBA graduates (in terms of salary, status, promotions, career change) and the nature of career barriers encountered. The UK data is based on a 1995/6 survey of over 200 MBA graduates conducted by one of the 
authors (Simpson, 1995; 1996; 2000). Results from this survey suggest women MBAs do not achieve 'career success' (as measured by pay and management status) to the same extent as men and that despite the MBA they are subject to attitudinal barriers located within the organization. The Canadian data is drawn from a similar study, conducted in 2000, of over 200 MBA graduates from one of the top business schools in Canada (Business Week, 2000).

Both countries have well established MBA programes with similar proportions (see above) of women on MBA courses. However, there are differences between Canada and the UK in terms of the emphasis placed on equity initiatives which may have an impact on career opportunities. Canada has a more pro-active and interventionist approach, as evidenced by a focus on affirmative action rather than equality of opportunity common in the UK (Gunderson, 1994a, 1994b). The gender gap in pay, for example, tends to be lower in Canada, where women earn on average $85 \%$ of men's weekly pay (Statistics Canada, 2002), than in the UK where the comparable figure is $75 \%$ (Labour Force Survey, 2002). The background of this study consequently provided an opportunity to assess whether women's career progress and experience of career barriers, similar to those that emerged from the UK study, might also exist for MBA graduates in a national culture where more official policies have been initiated and supported to promote women at work. The results of this study are presented below.

The paper is organized as follows. After a review of the literature on gender differences in benefits from the MBA and on career barriers, we discuss feminist orientations towards the role of qualifications in career success. We then set out the aims of the research and the methodological approach adopted. From the results presented, we identify three levels of barriers which operate at the micro level (person centred barriers), the intermediate level 
(organizational attitudes and practices) and the macro level (equal opportunities frameworks). We argue that, because the MBA is unable to overcome barriers at all levels, the qualification can reduce but not eliminate gender disadvantage in the workplace. In our conclusion we present a model of the 'MBA effect' which incorporates the levels of barriers above. We use this model to make interpretations concerning the differential career progress of women in Canada and the UK.

\section{Previous Research}

\section{Gender Differences in Career Benefits from the MBA}

Research to date indicates important career benefits from the MBA in terms of salary and managerial status (AMBA, 1996, Catalyst, 2000b; Business Week, 2002), increased confidence and credibility (Simpson et al, 2004; Sturges et al, 2003) as well as organizational benefits from improved managerial perfomance (Baruch and Peiperl, 2000). In a UK study of MBA graduates, Schofield (1996) found that within eighteen months, a half of MBA graduates were promoted and a half of those were promoted more than one step up. A similar situation emerged in Canada: Business Week (1997) has estimated that graduates from the top Canadian business schools can be expected to recoup their investment within two years by moving into top jobs and higher salary brackets. However, research also suggests a 'gender' gap in post MBA careers with women MBA graduates failing to reach equivalent positions to men in terms of both seniority and pay. In the US, for example, men advance further than women in both line positions and reporting span (Catalyst, 2000b). At the same time, they achieve more promotions (Cox and Harquil, 1991), have higher starting salaries (ibid) and larger subsequent pay rises so that the salary gap between men and women often 
widens over time (Roman, 1990; Gitlow, 1992; Schneer and Reitman, 1990). Similar findings on gender disparities in returns from the MBA also emerged from the UK study (Simpson,1996; 2000). Fewer UK women reached general management positions after graduating from the course and the gender difference in salary levels increased post MBA.

\section{Career Barriers}

While there has been little work on the extent to which the MBA may help to break down career barriers for women, much evidence has been gathered over the years on the nature of such barriers. These fall into two main categories (Powell, 2000): barriers that are 'personcentred', including personality traits, skills and behaviours that are contrary to the demands of managerial roles, and 'situation-centred' i.e. barriers located within the work and sociocultural environment. Person centred explanations suggest, for example, that women may lack certain key skills or have inappropriate education backgrounds. Alternatively, they may prioritise work-life balance and job satisfaction over traditionally 'male' notions of career success. Accordingly, women may be less willing than men to make the sacrifices in time and energy that full commitment to pursuit of rapid advancements in salary, status and managerial level demands. This was borne out by a Canadian based study of women managers (Burke, 1999) which found that having children had negative consequences for careers (judged by the above criteria) as women made choices concerning work-life balance.

The broader 'situation centred' explanations are divided by Oakley (2000) into those barriers that are located in corporate practices and barriers that have attitudinal and cultural causes. Within the former category, corporate policies and practices in training and career development, promotion and compensation are identified as major components of the glass ceiling that prevent women from making it to the top. This can be seen in a reluctance to 
promote women into line management positions (Lublin, 1996), a lack of diversity awareness and diversity initiatives (Cassell, 2000) as well as a lack of leadership training (Morrison, 1992). These deficiencies contribute to compensation practices that disadvantage women. Within the attitudinal and cultural explanations, negative stereotypes may see women as less logical and consistent and therefore less able to make tough decisions (Heilman et al, 1989) and less suited to top management positions (Powell, 1993). For example, differences in perceived communication and leadership styles are often based on the view that women are less assertive, that they lack self-confidence and have difficulty exercising authority (Tannen, 1994; Powell, 1993). Management is therefore seen as a masculine domain and normatively male (Schein, 1973; Marshall, 1984; Hearn and Parkin, 1988). This has implications for women who may experience resistance from men if they aspire to occupy senior roles (Cockburn, 1991; Gutek, 1985) on the grounds that they are challenging traditional values about sex roles and the (subordinate) 'placing' of women in organizations. Such resistance can take the form of exclusive networking and a 'men's club' culture which marginalises women and cuts them 'out of the loop' in terms of information sharing, sources of guidance and the establishment of relationships (Coe, 1992; Rindfleish and Sheridan, 2003; Zelechowski and Bilimora, 2003). The resultant exclusion from key aspects of organisational life can be a severe disadvantage to women in terms of furthering their careers (Ibarra, 1992; Burke et al, 1995).

\section{Theoretical Background}

The role of qualifications in career success has been part of the debate surrounding the career progress of women. The need to enhance individual attributes in order to compete on an equal footing with men is central to liberal feminism which focuses on individual attributes and 
how to increase the power and influence of women by working within existing (gender neutral) organizational structures. The need to enhance personal attributes (education, management skills) and to change discriminatory corporate practices, discussed above as person centered and corporate practices approach, is based largely on the liberal feminist assumption that reform within the existing structures and policies of the corporation will eventually result in greater equity in gender representation at the top. Therefore, if, on the supply side, women gained more expertise and adopted more male patterns of career planning (person centred approach) and if, on the demand side, this was buttressed by a commitment to equal opportunities in the workplace (corporate practices approach), then their career progress would be enhanced. Still (1992) for example has referred to the need for women to gain the right qualifications and skills and Burke and McKeen (1994) argue that many women, in tacit acceptance of this approach, embark of higher level qualifications such as an MBA in order to try to overcome some of the barriers they face in their careers.

Critiques of liberal feminism focus on its assumption of gender neutral bureaucratic structures and its inability to explain the underlying causes of disadvantage. Accordingly, radical feminists focus on patriarchal forms of power that are embedded in the bureaucratic organization (e.g. Ferguson, 1984), in gender based power dynamics (e.g.Cockburn, 1991) and in norms and values that prescribe women's subordination (e.g. Marshall, 1984). The focus is therefore on women's oppression and exclusion within systems of male power and advantage (Walby, 1990). This forms the basis of the cultural explanation of factors behind the glass ceiling, discussed above. On this basis, organizational structures and barriers hidden within the organisation, particularly within the informal context, may outweigh any individual differences in attributes (Cassell and Walsh, 1994). Hence, the power of the MBA to affect 
career progress and overcome career barriers can be neutralised by structural factors. 'Hidden' organizational barriers may override individual characteristics such as qualifications and skill so the MBA may not be effective in securing career success. These issues and debates are of central importance to this study of the career progress of women MBAs.

\section{Research Aims and Research Method}

Against this background, this research project on female MBA graduates has the following aims:

- to compare the profile of female MBAs in Canada and the UK

- to explore the extent to which female MBAs in Canada and the UK gain career benefits (e.g. pay, management status, promotions, career change)

- to explore the nature of career barriers experienced by female MBAs in Canada and the UK and to assess the extent to which the MBA has helped graduates to overcome career barriers

- to draw comparisons, where appropriate, with men in each national context

- to develop a model to explain any differences found between women in Canada and the UK in career progress and experience of career barriers

The UK study was conducted in 1995/6 and was based on a sample of MBA graduates from eleven business schools which, out of the fifteen contacted, had agreed to take part in the survey. Schools were chosen on the basis of having large and well established programmes. A total of 553 questionnaires was sent to MBA graduates through their alumni associations. Two hundred and twenty one were returned, making a response rate of $39.9 \%$. The sample comprised 130 male (59\%) and 91 female (41\%) MBA graduates. This female ratio is slightly above the ratio for the UK MBA population. The Canadian study was conducted in 2000 and 
was drawn from a leading business school which had agreed to collaborate in the survey. Unlike the UK study, the Canadian survey has therefore relied on one MBA provider. Logistical problems associated with questionnaire distribution from UK based researchers, together with difficulties gaining permission to use business schools' alumni details, meant that a broader based sample was not possible within the project's time frame. This narrower base may well limit the generalizability of the findings. However, the school in question is a large provider of MBA programmes and draws its student population from a wide geographical area.

Six hundred questionnaires were sent to MBA graduates in Canada through the alumni association. Two hundred and twenty five were returned, making a response rate of $36.8 \%$. The sample size and the response rate were therefore very similar to those of the UK. The sample comprised 140 male (63\%) and 81 female (37\%) MBA graduates. This ratio is broadly in accordance with the Canadian MBA population (see above).

To control for the effects of time on career progress, only those graduates who had been in the labour market for between one and two years with their qualification were included ie all those who had qualified more than two years prior to the survey taking place were excluded from the analysis. This does not fully eliminate the influence of time on career progress. On the one hand, there are likely to be considerable time related variations in career progress within that period. On the other hand, the 1-2 year gap between the survey and completion of the MBA may be insufficient for major career changes to be charted. A longitudinal study of MBAs would overcome these problems. 
The questionnaire in Canada was the same as the one used in the earlier UK study with the exception of one question which explored 'intrinsic' outcomes of the MBA (confidence, credibility, job satisfaction). This was not included in the UK survey. The importance of intrinsic outcomes emerged from a small number of interviews conducted with UK graduates after the survey. Such outcomes were subsequently included in the Canadian questionnaire. The questionnaire covered three key areas. The first section, About You, aimed to gather information on the profile of the MBA graduate in terms of age, qualifications, marital status, children and the impact of children on careers. The second section, Your Employment and the $M B A$, sought information concerning the career progress of MBA graduates as measured by changes in pay, management status and promotions as well as (in the Canadian survey) an assessment of intrinsic outcomes. The final section Your MBA and Career Barriers required information on barriers experienced in the form of personal barriers (e.g. caring responsibilities, lack of confidence, insufficient education), detrimental corporate practices (e.g. inflexible working practices, lack of training provision, lack of career guidance) and culture and attitudes (e.g. exclusive networks, prejudice from colleagues, negative attitudes to women managers). These categorisations were drawn from Powell (2000) and Oakley (2000) discussed above.

Data gathered was based on self reports and as such may have undermined the reliability of findings through the introduction of personal bias and 'post-rationalisation' (Vinnicombe and Singh, 2003). Both may lead respondents to overstate the benefits from the course. This may be less problematic in eliciting objective data on career change (e.g. pay, position, number of promotions, career change) though there may be some distortion through self justification and 'personal bias' (Baruch \& Peiperl, 2000) in more subjective data e.g. on the extent to which 
the MBA was perceived to have benefited careers. Equally, identification of career barriers may be influenced by levels of awareness rather than actual experience. For example, differences in the way men and women talk about success (Tannen, 1994) may explain some of the gender variation in perceptions of career barriers. The authors know of no research, however, where this may be influence identification of barriers across cultures.

Results from Canada were then compared with the UK study under various categories so that key differences and similarities could be highlighted. Categories followed the main themes of the questionnaires namely personal and work profiles, career progress and experiences of career barriers. Where there were difficulties drawing international comparisons on career progress (e.g. lack of comparability of salary scales, differences in management hierarchies), the relative position of women with men in each national context was examined. Similarly, gender differences in career barriers were examined in each country in order to establish the type of barriers that relate specifically to women. Comparisons of female MBAs in Canada and the UK were made test. for personal profile, some measures of career progress, as appropriate, and for experience of career barriers. As the data was predominantly nominal the chi square test was used as an appropriate non parametric statistical technique. This has been recommended in cross national research where tests are to be conducted on relationships between two nominal variables (see Ember and Ember, 2001).

In any cross national study, issues arise concerning the comparability of data (ibid). For example, the time lag between the collection of data in the UK and Canada (and the different macro-economic conditions prevalent at the time) may well have influenced some of the findings. Data in the UK was collected during a period of low growth while the survey in 
Canada was conducted under more robust economic conditions. This may have created some bias in responses pertaining to assessments of future prospects and of the role of the MBA in facilitating career progress

\section{Results}

\section{General Profile}

Women MBA graduates in Canada tended to be younger than counterparts in the UK and were less likely to be married or to have children. For example, nearly two thirds of women in Canada were aged between 25 and 34, compared with just over one third of women in the UK. At the same time, $63 \%$ of women were married in Canada and $25.9 \%$ had children compared with $70.3 \%$ and $36.3 \%$ respectively in the UK. Similar demographic trends occurred for men.

Insert table 1 here

The majority $(76 \%)$ were working in the private sector at the time of the survey while in the UK over a half (58\%) of women were in the public or voluntary sectors. In both contexts, nearly all women were working full time and, in terms of academic background, the vast majority had a first degree as their highest pre-MBA qualification. However, women in the UK had a more 'traditional' academic background in arts and humanities so that, given the concentration of men in science and engineering, there was a significant gender difference in this respect. No such difference emerged in Canada where both men and women came from a broad range of first-degree disciplines.

In Canada and the UK, the main motive for taking the MBA, for both men and women, was to improve job opportunities. The desire for a career change, for a business/academic 
qualification and for intellectual stimulation were also popular choices. In Canada women were significantly more likely than men to be motivated by a desire for a career change $(\mathrm{P}<0.01$, Chi square: 5.218). They were also more likely than women in the UK to be motivated in this way $(\mathrm{P}<0.01$, Chi square: 3.22). At the same time, $\mathrm{UK}$ women were more likely than Canadian counterparts to be motivated by intellectual stimulation $(\mathrm{P}<0.01$, Chi square: 8.41$)$ and by a desire to obtain general skills (P < 0.01; Chi square: 16.97). Results are summarised in Table 2.

Insert table 2 here

\section{Career Progress}

Canada

In Canada, both men and women moved out of functions such as marketing and IT into finance and, to a lesser extent, into consultancy so that post MBA one half of graduates were involved in these two activities. Women were particularly dynamic in this respect. For example, the proportion of women in finance doubled after the MBA indicative of substantial career change.

Both men and women moved out of professional/technical roles and junior management into more senior positions. There were no significant gender differences in proportions in general management before or after the MBA or in seniority of role. However, women experienced a much larger move into senior management (from 9\% to 24\%) compared with men (from $18 \%$ to $23 \%$ ). Three quarters of both men and women felt their prospects were good and between $33 \%$ and $40 \%$ had achieved one promotion since graduation from the course. Twenty per cent of men and women changed career. No gender difference emerged in terms of the nature of that progression (e.g. same organization, different organization). Some gender differences did 
occur in terms of pay. While there was some evidence of a gender gap in pay before the MBA, this gap widened after the course. For example, one half of men and nearly two thirds of women earned under $\$ 60,000$ before the MBA. At the other end of the scale, $15.2 \%$ of men and $10.3 \%$ of women earned over $\$ 100,000$. After the MBA, however, the pay difference widened at the lowest pay scale with $3.6 \%$ of men and $17.1 \%$ of women in this bracket $(\mathrm{P}<0.001$, Chi square: 11.440). A significant difference also emerged at the higher pay scales. Over a half of men $(53 \%)$ and one third of women earned over $\$ 100,000(\mathrm{P}<0.01$, Chi square: 7.149).

In terms of other, more personal benefits, women were more likely than men to value 'intrinsic' outcomes from the course where the value placed on such outcomes was measured on a 5 point Likert scale. Accordingly, women were more likely to choose points 1 and 2 (highly valued) for enhanced credibility (72.3\% of women and $61.3 \%$ of men), higher levels of job satisfaction (40\% of women and $29 \%$ of men), greater interpersonal skills (39\% of women and $28 \%$ of men) and greater assertiveness (56\% of women and $35 \%$ of men). The latter was significant though only at the $10 \%$ level $(\mathrm{P}=0.1, \mathrm{~F}=3.335)$. Results are summarised in Table 3.

Insert table 3 here

Overall, men and women were equally enthusiastic about the impact of the MBA on their careers. Over a half of graduates felt the MBA had helped their careers to a large extent. Only $4 \%$ felt it had not helped 
$\underline{\mathrm{UK}}$

Women's career path in the UK was in many ways less dynamic than in Canada and followed more traditional lines. As we have seen, women were concentrated in the public and voluntary sectors. They were also concentrated in gender typical support functions such as administration, education/training and personnel. After the MBA, while there was a trend for women to move out of such functions into general management, they were still concentrated in these areas and were much less likely than men to move into general management positions (generally associated with seniority). Only $24 \%$ of women and $31 \%$ of men were in general management post MBA.

As in Canada, there were no significant gender differences in terms of movement into senior roles post MBA. One third of men and women achieved one promotion after the course, which women tended to achieve by moving organization. However, only one fifth of women saw their prospects as good - compared to three quarters in Canada $(\mathrm{P}<0.001$; Chi square: 51.902). Only $5 \%$ of women changed career compared with $20 \%$ in Canada $(\mathrm{P}<0.01$; Chi square: 8.909). While there was some gender difference in pay before the MBA, particularly at the lowest and highest pay scales, after the MBA gender differences in pay widened so that one fifth of men and only $4.4 \%$ of women were in the top pay bracket $(\mathrm{P}<0.01$, Chi square: 10.08272).

A significant difference between women in Canada and the UK emerged in terms of the extent to which the MBA was thought to have helped in their careers. In the UK, only one fifth of women felt the MBA had helped their careers and $16 \%$ felt it had not helped. In Canada the corresponding figures were $50 \%$ and $4 \%$ respectively $(\mathrm{P}<0.001$; Chi square: 
27.478).

\section{Career Barriers}

The top two barriers identified by women in Canada were lack of career guidance and exclusive/closed networks followed by inflexible working practices and lack of training provision. Some significant gender difference $(\mathrm{P}<0.1$; Chi square: 3.088) occurred with respect to inflexible working practices (32\% of women and $21.4 \%$ of men). There were no other significant differences between men and women in Canada in terms of perceptions of career barriers. Nearly one fifth of women claimed to have experienced no barriers.

In the UK survey, high proportions of women claimed to have experienced exclusive/closed networks (56.1\%) and prejudice of colleagues (39.6\%). These were chosen over other barriers such as lack of career guidance, lack of training or insufficient education. Lack of confidence was also a problem for $36 \%$ of women. Highly significant gender differences emerged with respect to exclusive networks $(\mathrm{P}<0.001$, Chi square: 55.924) and prejudice of colleagues $(\mathrm{P}<0.01$, Chi square: 9.487). Only $8 \%$ of women claimed no barriers.

\section{Insert table 4 here}

Overall, comparing gender difference in career barriers, significant differences in the UK emerged for mainly attitudinal barriers while the one significant gender difference in Canada related to corporate practices (inflexible work practices). Comparing women in Canada with women in the UK reveals a similar pattern. Women in the UK were more likely than women in Canada to identify attitudinal barriers (prejudice, exclusive networks) while Canadian women were more likely to identify barriers relating to corporate practices (inflexible work practices, lack of career guidance). Significant differences between UK and Canadian women emerged in terms of inflexible work practices (32\% in Canada and18.7\% in UK) and lack of 
career guidance (44.4\% in Canada and $29.7 \%$ in UK) experienced by higher proportions of Canadian women, as well as lack of confidence (19.7\% in Canada and $36.3 \%$ in UK), prejudice from colleagues (19.7\% in Canada and 39.6\% in UK) and exclusive networks (39.5\% in Canada and $56.1 \%$ in UK), experienced by higher proportions of women in the UK. Interestingly, men in Canada were more likely than men in the UK to identity lack of career guidance and exclusive/closed networks while men in the UK were more likely to choose prejudice of colleagues.

Respondents were asked to assess the attitude within their organization to women managers. Here, a further significant difference emerged between women in Canada and the UK. Canadian women were generally more optimistic in this respect. Two thirds of women in Canada and $48 \%$ in the UK felt that attitudes to women managers in their organization were positive. At the other end of the scale, only $9 \%$ of Canadian women and $28 \%$ of UK women felt that attitudes were negative (see Table 5).

\section{Insert Table 5 here}

While lack of childcare facilities did not emerge in either context as a major career barrier, women in Canada were more positive than in the UK about the impact of caring responsibilities on careers: only one quarter of women with children in Canada felt that these responsibilities been detrimental compared to one half of women with children in the UK $(\mathrm{P}<$ 0.01; Chi square: 7.552).

Two thirds of women in Canada and the UK felt the MBA had helped them to overcome career barriers (either to some extent or to a large extent). One third felt the MBA had not 
helped in this way. In the UK, women making this claim were largely those who had chosen exclusive networks and prejudice as career barriers. In Canada, the one third of women making this claim was largely made up of those who claimed no barriers. There were no significant gender differences in either context.

\section{Discussion}

This project set out to explore how women in Canada and the UK benefit from the MBA and the nature of career barriers encountered in each context. Some similarities and differences emerged.

\section{Career Progress}

In terms of career progress, women in Canada had a more dynamic career path (as measured by career change and movement into senior roles) and were involved in less traditionally female activities and functions, with clusterings in high growth areas such as finance and consultancy. While women in the UK progressed in their careers and some moved out of traditional functions such as education/training and HR, concentrations in these areas remained. Research suggests that many women managers become confined to and progress up 'functional chimneys' and that this can be a severe disadvantage both in terms of acquiring general management skills necessary for more senior positions (Woodall et al., 1997) and in terms of reducing their visibility and power (Sheridan et al, 1990). Together with the low proportion of women in general management compared with men, this may indicate career progress of this nature in the UK.

Differences in the personal profile of women in Canada and the UK may help to explain the greater gender convergence in Canada. Women in the Canadian sample were, unlike in the 
UK, concentrated in the private sector where prospects more closely reflect macro-economic conditions and which may offer more opportunities for advancement. They were also younger than women in the UK and were less likely to be married or to have children. Previous research has emphasised the detrimental impact of family responsibilities on careers (e.g. Davidson and Cooper, 1992; Laufer, 1998; Coe, 1992) supporting Beechey's (1977) view that a major factor behind women's disadvantage in the labour market lies in their domestic responsibilities.

At the same time, the interventionist approach in Canada towards employment equity, where the emphasis is more pro-actively on equality of outcomes rather than equality of opportunity as is the case in the UK (Gunderson, 1994a, 1994b), may well have reaped rewards in terms of facilitating women's career progress. Canada has strong legislative and regulatory requirements which place emphasis on positive discrimination and where the onus of responsibility for monitoring success lies with employers. For example, employers must include in their annual reports to Human Resources Development Canada (HRDC) the measures they have taken to implement employment and pay equity as well as results achieved. The UK, by contrast, has focussed on creating a 'level playing field' where unequal outcomes in terms of jobs and resources are seen as the result of unequal merit (Webb, 1997) and where the 'onus of proof' of discrimination or disadvantage lies with the individual. However, as Liff (1989) and Collinson et al (1990) point out, formalisation of procedures does not assure their implementation. Such procedures can be evaded by neglect or design and are therefore no guarantee of substantive change. Unlike in Canada where HR departments have a central strategic role in the organization particularly in relation to employment and pay equity (Jain, 1997), such departments in the UK can be institutionally 
weak (Webb, 1997) and may contribute to a culture of non-compliance and evasion (ibid). Overall, looking at Canadian and UK data on career prospects and the role of the MBA in helping careers, the positive attitude of Canadian women may be symptomatic of the more favourable conditions for women in that context. Therefore the history and prioritization of such programs in Canada may explain some of the gender convergence in careers found among male and female Canadian MBAs.

However, in accordance with work by Roman (1990), Gitlow (1992) and Cox and Harquil (1991), women in both contexts are still disadvantaged in terms of pay. Evidence suggests this pay gap widens post MBA - a situation that conforms with Schneer and Reitmen's (1994) study of MBAs which found a wider gender gap in pay by mid career compared with an earlier career stage. It also conforms with more general UK data indicating a widening gender gap at higher pay levels (National Managememt Salary Survey, 1996). Reasons for the continuing gender gap in pay remain unclear. One explanation concerns differences in social networks (Petersen et al, 2000; Seidel, 2000) which mean that women, lacking ties with influential personnel, face disadvantages through lack of information and influence in pay negotiation processes. Gender differences in career aspirations may be a further factor. Some research (e.g. Eagly et al, 2000; Wigfield et al, 2000) suggests that women have different aspirations from men and may be less likely to have senior management as a goal - though this has been contested by other work (e.g. Powell and Butterfield, 2003) suggesting few gender differences in this respect. Either way, men and women may have different perceptions of career success, as outlined by Sturges (1999) and Russo et al (1991), which may feed into pay differentials. According to this view, men tend to place priority on extrinsic benefits of pay and status while women emphasise intrinsic factors such as job satisfaction 
and challenging work. The greater value placed by women in Canada on intrinsic benefits from the MBA, compared with Canadian men, may go some way to support this view.

While we have no matching UK data on intrinsic benefits from the MBA, the greater value placed on these benefits by women in Canada is interesting in its own right. This may reflect not only different definitions and prioritisations of career success as outlined by Sturges and Russo et al above, but also the advantages of credibility and personal status already conferred on men by their gender. As Melamed (1996) points out, qualification levels are objective merits which are likely to enhance credibility and which may be more beneficial to women (who are already disadvantaged in this respect) than to men who have less difficulty assuming a managerial role. A similar situation may exist with levels of assertiveness: if men have less difficulty behaving assertively than women, they are less likely to identify this as an outcome of the MBA.

\section{Career Barriers}

Previous research in both Canada (e.g. Catalyst, 2000a; Burke, 1994) and the UK (e.g. Coe, 1992; Cockburn, 1991; Maddock and Parkin, 1994; Vinnicombe and Singh, 2003) has highlighted the detrimental effects of attitudinal and cultural barriers such as negative stereotypes and 'old boys networking' for women's careers. This conforms with results from the UK survey which suggests women identify cultural barriers associated with exclusive networks as well as prejudicial and negative attitudes. In fact, women in the UK survey stand out in comparison to men and in comparison to women in Canada in their emphasis on attitudinal/cultural barriers.

Women in the Canadian survey, however, have a different and possibly lesser experience of 
career barriers. In this respect, barriers associated with corporate practices stand out as a particular problem. For example, Canadian women are more likely than women in the UK to identify lack of training provision and lack of career guidance and they differ from Canadian men and from UK women in their experience of inflexible working practices. Therefore, while training provision and career guidance are identified by men and women alike, inflexible working practices emerge as a 'gendered' barrier. At the same time, while exclusive networks and prejudice within the organization were specifically associated with the female experience in the UK, there was little or no gender difference in Canada.

While the gendered nature of inflexible working practices in Canada may reflect women's greater experience of work-home conflict (Beatty, 1996) as well as their growing dissatisfaction with, and many men's continued acceptance of, long and inflexible hours (Goffee and Nicholson, 1994; Powell, 2003), it is unlikely that these are less of an issue for women in the UK. One possible explanation is that in the UK negative attitides and prejudice are pressing problems which overshadow other issues such as work inflexibility or lack of career guidance. Alternatively, women in Canada may be more critical and less accepting of work practices which they feel act against them. Either way, corporate practices may emerge as particular problems once other more deepseated and intractable barriers have been reduced.

\section{Can the MBA Overcome Career Barriers?}

According to Simpson (2000) and Leeming and Baruch (1998), the MBA can be a vehicle for helping women break through the glass ceiling - and the progress women make in their careers since graduation from the course may be some testimony to this effect. However, the 'effectiveness' of the MBA must partly depend on the nature of barriers experienced. As an individual attribute, the MBA may be expected to overcome 'person-centred' barriers more 
than any other - for example by enhancing confidence, credibility and management skills as well as changing career aspirations. For women in Canada, enhanced credibility and assertiveness are important MBA outcomes - and this may influence women's ability to act as change agents by exploiting opportunities (e.g. by seeking out and achieving career change) and/or by challenging the status quo (e.g. by moving into gender a-typical activities and functions). However, while there is no matching UK data on the above, lack of confidence remains a particular problem for women in the UK - possibly as a direct result of the difficulties they face in the workplace. Qualifications alone are unlikely to change detrimental attitudes. Perhaps for both these reasons (intractable career barriers, lack of confidence) women do not achieve the same career outcomes as men and the gender gap in career progress is consequently larger in the UK.

This means the 'effectiveness' of the MBA in helping women break through the glass ceiling is likely to depend on diverse factors and that these factors interact to influence the relative strength or weakness of such an 'MBA effect'. At the macro level, legislative frameworks on equal opportunities and employment equity are likely to impact on career barriers. At a more intermediate/organizational level are barriers associated with corporate practices and with organizational culture and attitudes while at the micro level are person centred barriers (e.g. lack of confidence, low levels of assertiveness, caring responsibilities).

The following model summarises the interdependence of these three levels of factors: 


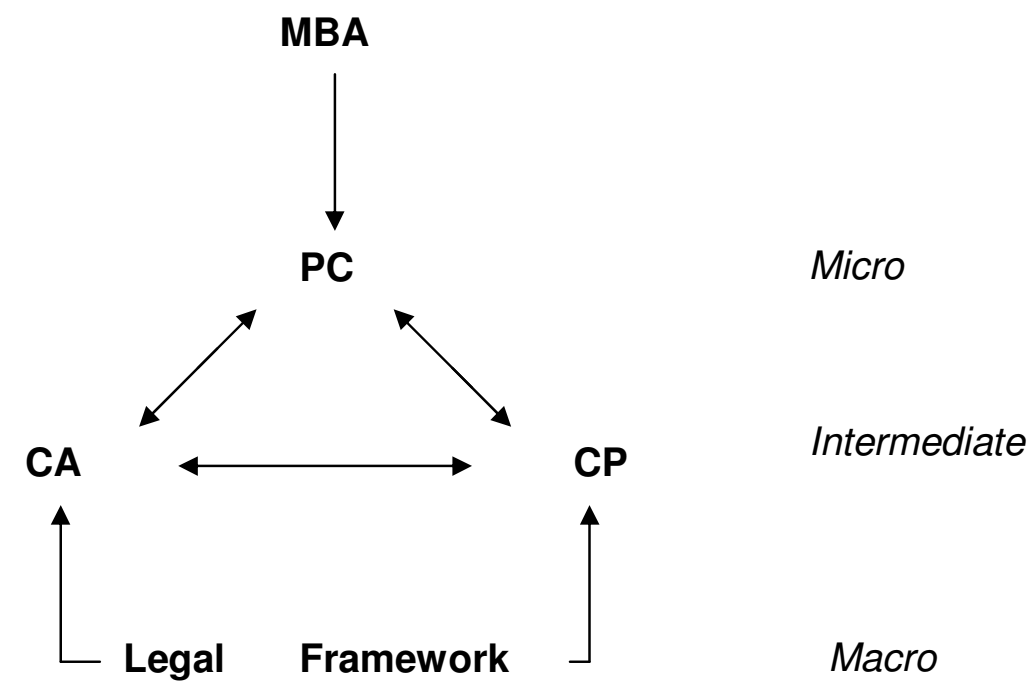

As the above model indicates, the MBA will have a stronger impact at the micro level on person centred barriers (PC), identitifed by Powell (2000) as a key explanation for women's career progress. On the other hand, at the 'macro' level, the underlying legal framework on equal opportunities will have a direct influence on organizational culture and attitudes (CA) and corporate practices $(\mathrm{CP})$, both located within the intermediate organizational level. Attitudes and practices have been identified by Oakley (2000) as broader 'situation-centred' barriers. Some interdependence between the three types of barriers is likely (as illustrated by the triangle of arrows). For example, organizational culture and attitudes can feed into corporate practices (and vice versa) and have an impact on person centred barriers. Accordingly, negative attitudes to women can create a hostile working environment and undermine women's self confidence and aspirations. Consequently, while the MBA will undoubtedly enhance confidence, credentials and credibility as well as introduce its graduates to new ways of working, negative attitudes at work can undermine self-confidence and consequently the ability of women to fully exploit their capabilities. Alternatively, where 
attitudes are more sympathetic to women, the MBA may enhance confidence and assertiveness sufficiently to encourage women to act as change agents and challenge the status quo.

This allows the following interpretations of the 'MBA effect' in Canada and the UK to be made. In the UK context, a weaker and less pro-active legislative framework may not have had as great an impact on attitudes to women in the workplace as in Canada. This may weakening women's ability to initiate and follow through change in their careers so that, despite the advantages of the MBA, they lag behind men. In other words, while the impact of the MBA on person centred barriers may be profound, this is undermined by weak pressure from equal opportunities frameworks on attitudes and practices. By contrast, a stronger and more proactive legislative framework in Canada may have helped to create a more "prowoman' environment. In this context, the impact of the MBA is less likely to be undermined by negative attitudes. Women are therefore more able to fully exploit the advantages of the MBA and this is reflected in career progress which is similar to that of men.

\section{Conclusion}

This research set out to explore the career progress of women MBAs in Canada and the UK and to investigate the nature of career barriers encountered in each national context. From this, an assessment can be made as to the the extent to which the MBA can help women overcome career barriers. Results suggest that the MBA can reduce but not eliminate gender disadvantage in the workplace. Its main impact will be on person centred barriers at the micro level but the effects can be undermined or strengthened at the 'macro' level by legislative frameworks and at the intermediate level by corporate attitudes and practices. The strength of 
the 'MBA effect' in terms of reducing career barriers and facilitating career progress will therefore vary across countries and will partly depend on national differences in social institutions and structures that influence the shaping of gender relations at work.

In terms of the debate over the role of qualifications in career success, this model indicates that it is not appropriate to think of any one theoretical approach in isolation and that a pluralist approach, which works with different explanatory frameworks, is more fruitful. Accordingly, the model incorporates the liberal feminist emphasis on individual attributes and equal opportunities frameworks as well as a more radical feminist focus on underlying attitudes and organizational culture. At the same time, it recognises the importance of agency and the capacity of women to challenge and ultimately change the status quo.

Important insights have been gained from this study on women's career progress with the MBA as well as the barriers they face and the role of the MBA in overcoming these barriers. As Adler and Izraeli (1994) note, inter and intra-country studies are important in order to better understand cultural influences limiting career advancement - particularly for women. Only by examining the commonality and the differential dynamics of career progression can we fully understand the factors that prevent many women, even those with an MBA, from reaching the top of the hierarchy and the factors that lie behind the paucity of women managers world wide. 


\section{References}

Adler, N. \& Izraeli, D. (1994), Competitive Frontiers Women Managers in a Global Economy, Blackwell

Association of MBAs (1996), MBA Salary and Career Survey, AMBA

Baruch, Y. and Peiperl, M. (2000), The Impact of an MBA on Graduate Careers, Human Resource Management Journal, Vol 10 No 2, pp. 69 - 90

Baruch, Y., Bell, M. and Gray, D. (2004) Generalist and Specialist Business Degrees: Tangible and Intangible Value, Journal of Vocational Behaviour (forthcoming)

Beatty, C. (1996) The Stress of Managerial and Professional Women: Is the Price to High?, Journal of Organizational Behaviour, Vol 17, pp. 233-252

Beechey (1987), Unequal Work, London: Verso

Bickerstaffe, G. (1992), Which MBA? A Critical Guide to the World's Best Programmes, 4th edition, London: The Economist Intelligence Unit

Burke, R. (1999) Are Families a Career Liability, Women in Management Review Vol 14 No 5 , pp 17-24

Burke, R. and McKeen, C. (1994), Career Development among Managerial and Professional Women, in Davidson, M. and Burke, R. (Eds) Women in Management: Current Research Issues, London: Chapman.

Burke, R. (1994), Women in Corporate Management in Canadian Organizations: Slow Progress?, Executive Development, Vol 7 No 3, pp. 36-48

Burke, R. Rothstein, M. and Bristor, J. (1995), Interpersonal Networks of Managerial and Professional Women and Men: Descriptive Characeristics, Women in Management Review, Vol 10 No 1, pp. 13-25

Business Week (1997), What's an MBA Worth?, R. Carpenter, Oct 31, issue 4

Business Week (2000) Ranking Global Programs 54, Oct 2.

Business Week (2002). Business Week Survey. www.businessweek.com

Cassell, C. (2000), The Business Case and the Management of Diversity, in Davidson, M. and Burke, R. (eds) Women in Management: Current Research Issues, London: Sage

Cassell, C. and Walsh, S. (1994) Falling Back or Fitting In, Cultural Barriers to Women's Progression in Management, paper presented to 1994 British Academy of Management 
Conference, Sept

Catalyst (2000a) Census of Women Board Directors of Canada, Catalyst New York

Catalyst (2000b) Women and the MBA: Gateway to Opportunity, Catalyst, New York

Coe, T. (1992), The Key to the Men's Club, Corby, Institute of Management.

Cockburn, C. (1991), In the Way of Women: Men's Resistance to Sex Equality in Organizations, London: MacMillan

Collinson, D., Knights, D. and Collinson, M. (1990), Managing to Discriminate, London: Routledge

Cox, T. and Harquil, C,. (1991), Career Paths and Early Career Success in the Early Career Stages of Male and Female MBAs, Journal of Vocational Behaviour, Vol 39, pp. 54-75

Davidson, M. \& Cooper, C. (1992), Shattering the Glass Ceiling, London, Paul Chapman.

Eagly, A., Wood, W. and Diekman, A. (2000) Social Role Theory of Sex Differences and Similarities: A Current Appraisal. In Eckes, T. and Trautner, H. (eds) The Developmental Social Psychology of Gender, Erlbaum, Mahwah, NJ 363-390

Ember, C. and Ember, M. (2001) Cross Cultural Research Methods, Alta Mira Press, CA 94596

Ferguson, K. (1984), The Feminist Case against Bureaucracy, Temple University Press, Philadelphia

Finney, M. (1996), Degree that Make a Difference, HR Magazine, Vol 41 No 11 pp.74-82

Gitlow, A. (1992), Being the Boss: The Importance of Leadership and Power, Homewood, IL,Irwin.

Goffee, R. and Nicholson, N. (1994), Career Development in Male and Female Managers: Convergence or Collapse, Burke, R. and Davidson, M. (eds) Women in Management: Current Research Issues, London: Chapman

Gunderson, M. (1994a). Pay and employment equity in the United States and Canada. International Journal of Manpower, Vol15, No 7, pp. 45-60

Gunderson, M. (1994b). Comparable worth and gender discrimination: international aspects, International Labour Office, Geneva

Gutek, B. (1985), Sex and the Workplace, Jossey Bass, San Francisco.

Hearn, J. and Parkin, W. (1987), Sex at Work. The Power and Paradox of Organization Sexuality, Wheatsheaf, Brighton: St. Martin's, New York 
Heilman, M, Block R., Martell, F. and Simon, C. (1989), Has Anything Changed? Current Characterizations of Men, Women and Managers, Journal of Applied Psychology, Vol 74 No 6 pp. $935-942$

Ibarra, H. (1992), Homophilly and Differential Returns: Sex Differences in Network Structure and Access in an Advertising Firm, Administrative Science Quarterly, Vol 8 No 2 pp. 35-47

Institute of Management (1998), “Annual Report”, IM

Jain, H. (1997), Employment Equity in Canada, Human Resources Management in Canada, November

Labour Force Survey. 2002. Office for National Statistics. London: HMSO

Laufer, J. (1998), Equal Opportunity between Men and Women: The Case of France, Feminist Economics, Vol 4 No1 pp.: 53-69

Liff, S. (1989), Assessing Equal Opportunities Policies, Personnel Review, Vol 18 pp. 27-34

Leeming, A. and Baruch, Y. (1998), The MBA as a Bridge over the Troubled Waters of Discrimination, Women in Management Review, Vol 13 No 3 pp. 95-104

Lublin, J. (1996), Women at Top are Still Distant from CEO Jobs, Wall Street Journal, Nov $10^{\text {th }}, \mathrm{B} 2$

Maddock, S. and Parkin, D. (1994), Gender Cultures: How they affect Men and Women at Work, in Burke, R. and Davidson, M. (eds) Women in Management: Current Research Issues, London: Chapman

Marshall, J. (1984), Women Managers: Travellers in a Male World, Chichester: John Wiley.

Melamed, T. (1996), Career Success: An Assessment of a Gender Specific Model, Journal of Occupational and Organisational Psychology, Vol 69 No 3 pp. 217-242.

Morrison, A. (1992), The New Leaders: Guidelines on Leadership Diversity in America, Jossey Bass San Francisco

National Management Salary Survey (1996) Institute of Management and Renumeration Economics, IM

Oakley, J. (2000), Gender Based Barriers to Senior Management Positions: Understanding the Scarcity of Female CEOs, Journal of Business Ethics, Vol 27 pp.321-334

Petersen. T., Saporta, I. and Seidel, M. (2000) Offering a Job: Meritocracy and Social Networks, American Journal of Sociology, Vol 106, No 3, pp. 763-816

Powell, G. (1993), Women and Men in Management, Sage Newbury Park, CA 
Powell, G. (2000), The Glass Ceiling: Explaining the Good and Bad News in Davidson, M. and Burke, R. (eds) Women in Management: Current Research Issues, Vol 2, London: Sage

Powell, G and Butterfield, D. (2003) Gender, Gender Identity and Aspirations to Top Management, Women in Management Review, vol 18 (8): 88-96

Rindfleish, J. and Sheridan, A. (2003) No Changer from Within: Senior Women Managers' Response to gendered Organizational Structures, Women in Management Review Vol 18, No 6, pp. 299-310

Roman, M. (1990), Women Beware: An MBA Doesn't Mean Equal Pay, Business Week 29 October, 47.

Russo, N., Kelly, M. \& Deacon, M. (1991), Gender and sex related attribution: beyond individualistic conceptions of achievement, Sex Roles, Vol 25, pp. 331-350

Schein, V. (1973), The Relationship between Sex Role Stereotypes and Requisite Management Characteristics Among Female Managers, Journal of Applied Psychology, Vol 57 pp. 89- 105

Schneer, J. and Reitman, F. (1990), The Importance of gender in mid-career: a longitudinal study of MBAs, Journal of Organizational Behaviour, Vol 15 pp. 199-207

Schofield, P. (1996), The MBA: Managers Only Please, Accountancy ${ }_{2} 117 / 1233$, pp40-42

Seidel, M., Polzer, J. and Stew, K. (2000), Friends in High Places: The Effects of Social Networks on Discrimination in Salary Negotiations, Administrative Science Quarterly, Vol 45 No 1 pp. 11-25

Sheridan, J., Slocum, J., Buda, R. and Thompson, R. (1990), Effects of Corporate Sponsorship and Departmental Power on Career Tournaments, Academy of Management Journal, Vol 33 No 2 pp. 578-602

Simpson, R. (1995) Is Management Education on the Right Track for Women, Women in Management Review, Vol 10, No 6, pp. 65-78

Simpson, R. (1996), Does an MBA Help Women?, Gender Work and Organisation, Vol 3 No 2 pp. 13-19

Simpson, R. (2000), Winners and Losers: Who Benefits Most from the MBA, Management Learning, Vol 31 No 2 pp. 45-58

Simpson, R., Sturges, J., Woods, A. and Altman, Y. (2004) Gender, Age and the MBA: An Analysis of Extrinsic and Intrinsic Career Benefits, Journal of Management Education (forthcoming)

Smeenk, B. (1993), Canada’s Pay Equity Experiments, HR Magazine, Vol 38 No 9 pp.58-62 
Statistics Canada, 1997, Census 1995, Ottawa: Ministry of Industry, Science and Technology

Statistics Canada. (2002). Women in Canada, Ministry of Industry, Science and Technology.

Stern, S. (2002) What do Business Schools Do for Them? Management Today, February, 4145

Still , L. (1992), Breaking the Glass Ceiling, Women in Management Review, Vol 17 No5, pp. 3-8.

Sturges, J. (1999), What it Means to Succeed: Personal Conceptions of Career Success Held by Male and Female Managers at Different Ages, British Journal of Management, Vol 10 pp. 239-252

Sturges, J., Simpson, R. and Altman, Y. (2003) Capitalising on learning: An Exploration of the MBA as a Vehicle for Developing Career Competencies, International Journal of Training and Development, Vol 7 (1): 53-67

Tannen, D. (1994), Talking from 9-5: How Women's and Men's Conversational Styles Affect Who gets Credit and What gets Done, William Morrow and Co. New York

Vinnicombe, S. and Singh, V. (2003) Locks and Keys to the Boardroom, Women in Management Review Vol 18, No 6, pp. 325-333

Walby, S. (1990) Theorising Patriarchy. Oxford: Blackwell

Webb, J. (1997), The Politics of Equal Opportunity, Gender Work and Organization, Vol 4 No 3 pp.159-169

Woodall, J., Edwards, C. and Welchman, R. (1997), Organisational Restructuring and the Achievement of an Equal Opportunity Culture, Gender Work and Organization, Vol 4 No1 pp2-12

White, B. (2000), Lessons from the Careers of Successful Women, in Davidson, M. and Burke, R. (eds) Women in Management: Current Research Issues, Vol 2, London: Sage

Wigfield, A., Battle, A., Keller, L. and Eccles, J. (2000). Sex Differences in Motivation, Self Concept, Career Aspiration and Career Choice: Implications for Cognitive Development in McGillicuddy-De Lisi, A. and De-Lisi, R. (eds) Biology, Society and Behaviour: The Development of Sex Differences in Cognition, Ablex, Westport, CT: 93-124

Zelechowski, D. and Bilimoria, D. (2003) The Experience of Women Corporate Inside Directors on the Boards of Fortune 1,000 Firms, Women in Management Review, Vol 18, No 7, pp 376-381 
Table 1: Demographic Information

\begin{tabular}{|l|l|l|l|l|}
\hline & \multicolumn{2}{|c|}{ Male } & \multicolumn{2}{c|}{ Female } \\
\hline & Canada & UK & Canada & UK \\
\hline Age: 25-34 & 50.4 & 23.4 & 63.3 & 34.1 \\
\hline 35-44 & 41.7 & 55.5 & 32.9 & 46.2 \\
\hline \multicolumn{1}{|c|}{$45-54$} & 7.9 & 21.1 & 3.8 & 19.8 \\
\hline Married & 75.0 & 90.8 & 63.0 & 70.3 \\
\hline With children & 44.3 & 66.7 & 25.9 & 36.3 \\
\hline N & & & & \\
\hline
\end{tabular}

Table 2: Motives for taking the MBA

\begin{tabular}{|c|c|c|c|c|c|}
\hline & Canada male & Canada female & UK male & UK female & $\begin{array}{l}\text { Significance } \\
(\mathrm{P}<0.01)\end{array}$ \\
\hline Improve job opportunities & 40 & 35.8 & 22.7 & 26.0 & 3 \\
\hline Change career direction & 18.6 & 32.1 & 14.8 & 13.4 & 1,2 \\
\hline Obtain business qualification & 14.3 & 19.8 & 14.8 & 15.7 & \\
\hline Increase salary & 2.1 & 2.5 & 2.3 & 3.9 & \\
\hline Intellectual stimulation & 19.3 & 8.6 & 20.5 & 18.9 & 2 \\
\hline Increase self confidence & 2.1 & 1.2 & 3.4 & 3.4 & \\
\hline Obtain general skills & 1.4 & 0 & 14.8 & 15.0 & 2,3 \\
\hline Improve performance in current job & 2.1 & 0 & 6.8 & 3.9 & \\
\hline$N$ & & & & & \\
\hline
\end{tabular}

1: significant gender difference (Canada)

2: significant difference between Canadian and UK women

3: significant difference between Canadian and UK men 
Table 3: Benefits from the MBA (Canada)

\begin{tabular}{|l|l|r|r|r|r|r|}
\hline Canada & SEX & N & Mean & $\begin{array}{c}\text { Overall } \\
\text { mean }\end{array}$ & \multicolumn{1}{c|}{$\mathrm{t}$} & Sig (2 tailed) \\
\hline Greater marketability/mobility & male & 139 & 1.9209 & 1.9269 & -.105 & .917 \\
\hline & female & 80 & 1.9375 & & & \\
\hline Enhance job prospects & male & 139 & 2.0000 & 1.9726 & .502 & .616 \\
\hline & female & 80 & 1.9250 & & & \\
\hline Enhance salary and status & male & 139 & 2.1871 & 2.1416 & .851 & .396 \\
\hline & female & 80 & 2.0625 & & & \\
\hline Enhanced credibility & male & 140 & 2.3500 & 2.2682 & 1.468 & .143 \\
\hline & female & 80 & 2.1250 & & & \\
\hline I am more confident in my job & male & 140 & 2.3000 & 2.3516 & -.169 & \\
\hline & female & 79 & 2.4430 & & & .334 \\
\hline Enhance confidence & male & 139 & 2.3885 & 2.3836 & .084 & .933 \\
\hline & female & 80 & 2.3750 & & & \\
\hline I can handle and analyze complex data & male & 140 & 2.3857 & 2.4773 & -1.615 & .108 \\
\hline & female & 80 & 2.6375 & & & \\
\hline I am more effective at meetings & male & 140 & 2.5500 & 2.5138 & .741 & \\
\hline & female & 78 & 2.4487 & & & \\
\hline I have improved my negotiation skills & male & 140 & 2.5143 & 2.5591 & -.938 & \\
\hline & female & 80 & 2.6375 & & & \\
\hline I can manage individuals/teams more effectively & male & 140 & 2.5643 & 2.5636 & .013 & \\
\hline & female & 80 & 2.5625 & & & .990 \\
\hline I am able to work more effectively with others & male & 140 & 2.6143 & 2.6318 & -.366 & \\
\hline & female & 80 & 2.6625 & & & .715 \\
\hline I have become more assertive in my dealings with others & male & 140 & 2.7214 & 2.6318 & 1.826 & .069 \\
\hline & female & 80 & 2.4750 & & & \\
\hline Higher levels of job satisfaction & male & 140 & 2.9786 & 2.8864 & 1.700 & .091 \\
\hline & female & 80 & 2.7250 & & & \\
\hline Greater interpersonal skills & male & 139 & 3.0360 & 2.9635 & 1.387 & .167 \\
\hline & female & 80 & 2.8375 & & & \\
\hline I am more sensitive to difference and diversity & male & 140 & 3.1500 & 3.1409 & .172 & .864 \\
\hline & female & 80 & 3.1250 & & & \\
\hline
\end{tabular}


Table 4: MBA Graduates and Experience of Career Barriers (\%)

\begin{tabular}{|l|l|l|l|l|l|l|}
\hline & $\begin{array}{l}\text { Women } \\
\text { UK }\end{array}$ & $\begin{array}{l}\text { Women } \\
\text { Canada }\end{array}$ & Significance & $\begin{array}{l}\text { Men } \\
\text { UK }\end{array}$ & $\begin{array}{l}\text { Men } \\
\text { Canada }\end{array}$ & Significance \\
\hline Inflexible working practices & 18.7 & $32.0 *$ & 0.032 & 19.3 & 21.4 & \\
\hline Lack of training provision & 24.1 & 30.8 & & 25.4 & 26.4 & 11.5 \\
\hline Insufficient Education & 7.7 & 8.6 & 12.9 & \\
\hline $\begin{array}{l}\text { Family commitments/childcare } \\
\text { problems }\end{array}$ & $14.3 *$ & 16.1 & & 2.3 & 12.1 & \\
\hline Lack of personal confidence & 36.3 & 19.7 & 0.013 & 26.9 & 21.4 & \\
\hline Lack of career guidance & 29.7 & 44.4 & 0.046 & 25.4 & 43.6 & $<0.01$ \\
\hline Prejudice & $39.6 *$ & 19.7 & 0.004 & 21.6 & 10.7 & $<0.025$ \\
\hline Exclusive/closed networks & $56.1 *$ & 39.5 & 0.014 & 8.4 & 33.6 & $<0.001$ \\
\hline No barriers & $7.7 *$ & 18.5 & 0.029 & 24.6 & 22.9 & \\
\hline
\end{tabular}

* significant differences with male counterparts

Table 5: Attitudes to women managers in the employing organization (\%)

\begin{tabular}{|l|l|l|}
\hline & Women in Canada & Women in UK \\
\hline Positive attitude & 63.3 & 47.7 \\
\hline Neutral attitude & 27.8 & 23.9 \\
\hline Negative attitude & 8.9 & 28.4 \\
\hline N & 79 & 88 \\
\hline
\end{tabular}

$P=0.006$, Chi square: 10.389 